\title{
Comunicación y sustentabilidad
}

Communication and sustainability

EDITORIAL

\section{Ruth S. Contreras Espinosa}

Universitat de Vic-Universitat Central de Catalunya

Profesora del Departamento de Comunicación. Editora de la revista Obra Digital.

ruth.contreras@uvic.cat

ORCID:0000-0002-9699-9087

\section{Resumen:}

La sustentabilidad es reconocida como la base de la responsabilidad social corporativa que se refiere al nivel de contribución que una organización hace al mejoramiento de la sociedad. Es interesante comprender cómo y qué organizaciones se comunican con sus receptores interesados con respecto a su marca o servicios, así como una consideración de cómo los informes de sostenibilidad varían según la variación geográfica. Los niveles de divulgación corporativa variarán según la región o el país, debido a las diferencias económicas y ambientales, así como a las condiciones sociales y culturales.

\section{PALABRAS CLAVE}

Comunicación, investigación, sustentabilidad, organizaciones.

\section{Abstract:}

Sustainability is recognised as the basis for corporate social responsibility which refers to the level of contribution an organization makes towards the betterment of society. An understanding of how and what organizations are communicating to their stakeholder groups regarding their brand or services, as is a consideration of how sustainability reporting varies according to geographical variation. Levels of corporate disclosures will vary depending on the region or country, due to economic and environmental differences as well as social and cultural conditions.

\section{KEYWORDS}

Communication, research, sustainability, organizations. 
Como parte del proceso de gestión de empresas y organizaciones, existe una mayor atención con respecto a la sustentabilidad, atribuible a la importancia estratégica para las organizaciones (Sahlin-Andersson 2006). El mayor enfoque en la sustentabilidad es en gran medida el resultado de las presiones de grupos de múltiples partes interesadas (Kolk 2008) para una mayor responsabilidad y transparencia organizativa en una amplia gama de problemas de comportamiento corporativo. Como tal, las organizaciones han ampliado sus informes corporativos para incluir voluntariamente información sobre temas de sustentabilidad e información sobre sus esfuerzos hacia la responsabilidad social.

La sustentabilidad es reconocida como la base de la responsabilidad social corporativa que se refiere al nivel de contribución que una empresa u organización puede hacer para el mejoramiento de la sociedad (Uhlaner et al. 2004). Empresas y organizaciones funcionan mejor cuando fusionan no solo sus intereses comerciales, sino también los intereses de sus partes interesadas. Es por ello que participar en informes de sustentabilidad que proporcionen necesidades claras a las partes interesadas puede proporcionar unos beneficios firmes. Los beneficios que pueden surgir incluyen opiniones positivas de los consumidores, mayor satisfacción de los empleados, apoyo de la comunidad, confianza de los interesados (Dean 2003) y, puede ayudar con la gestión de la marca corporativa. En este ultimo caso, se requiere un esfuerzo estratégico para presentar un valor agregado de identidad de marca. Es decir, la marca comunica cualidades, valores y promesas corporativas, lo que ayuda a las empresas y organizaciones con el objetivo final de mostrar una reputación corporativa positiva. Por lo tanto, es interesante comprender cómo y qué organizaciones se comunican, al igual que es interesante considerar cómo los informes de sustentabilidad varían según la variación geográfica (Raar, 2002). La velocidad y la distribución geográfica de los informes relacionados con sustentabilidad es notable, con un crecimiento constante evidente tanto en el número como en el tipo de organizaciones que abarcan el mecanismo de informes. Sin embargo, es probable que los niveles de revelaciones varíen dependiendo de la región y el país, debido en parte a las diferencias económicas y ambientales, así como a las condiciones sociales, culturales y los requisitos legislativos nacionales (Jamali y Mirshak 2006).

La revista Obra Digital, ha sentido la responsabilidad de atender esta área en crecimiento. Nuestro presente número, correspondiente a los meses de febrero a agosto de 2019, se nutre de 7 artículos en el bloque del monográfico que se titula "Retos desde la Comunicación para la Sustentabilidad". Existe la necesidad de entender mejor todos aquellos temas relacionados con la comunicación y la sustentabilidad, y abordar todas aquellas cuestiones relacionadas con su entorno. Así como también, existe la necesidad de una perspectiva geográfica con respecto a ello. Como se ha mencionado antes, los informes relacionados con sustentabilidad varían dependiendo de la región y el país, debido a sus diferencias económicas, ambientales, sociales, culturales o por requisitos legislativos. De ahí la importancia de prestar atención a otras regiones menos estudiadas y no centradas solo en América del Norte, Europa y Asia.

En los artículos de este número 16, los autores establecen un cuerpo holístico de conocimiento. Además de describir diversas prácticas en algunas regiones como Ecuador o Brasil, contextualizan dicha práctica al vincularla con variables socioculturales. Este monográfico evidencia además que los autores, como expertos, están en una buena posición para describir el estado de la cuestión. Cada vez más organi- 
zaciones que miden la sustentabilidad lo hacen a través de un enfoque simultáneo, con indicadores económicos, sociales y ambientales (Wheeler y Elkington, 2001). Porque para ser sustentable, se debe ajustar la organización a las expectativas de la sociedad y minimizar o eliminar cualquier impacto negativo sin ningún perjuicio.

Por otro lado las tareas de las organizaciones se han simplificado debido a la propagación de la tecnología. Dada la plétora actual de fuentes electrónicas, y la velocidad con la que una persona puede investigar un informe, las organizaciones prestan mayor atención a sus sitios web, y redes sociales. Las dos formas más comunes en que los usuarios aprenden sobre el compromiso de las organizaciones con la sostenibilidad son las fuentes electrónicas, como los sitios web. La facilidad de acceso a diversas fuentes electrónicas indica que no sería prudente que una organización no sea fiel y clara. De hecho, las revelaciones de una organización deben reflejar con precisión acciones reales, en lugar de retóricas o sesgos. Una organización que sea honesta y que evite los informes sesgados ganará mayor credibilidad y mantendrá la legitimidad. Como tales, las organizaciones deben garantizar que sus revelaciones sean un reflejo del comportamiento preciso y no simplemente un dispositivo de legitimidad.

Los trabajos reunidos en el monográfico entonces, confirman el interés de la comunidad académica en este tema. Creemos que esta publicación resultará beneficiosa para aquellos profesionales y estudiantes especializados en la comunicación, la sustentabilidad y las responsabilidad social corporativa.

No quiero cerrar este texto, sin invitar además a nuestros lectores a consultar los dos artículos de miscelánea que conforman nuestro número dieciséis.

\section{Referencias}

Dean, D. H. (2003). Consumer Perception of Corporate Donations: Effects of Company Reputation for Social Responsibility and Type of Donation. Journal of Advertising, 32(4), 91-102.

Jamali, D. and Mirshak, R. (2007). Corporate Social Responsibility (CSR) Theory and Practice in a Developing Country Context. Journal of Business Ethics, 72,243-262.

Kolk, A. (2008). Sustainability, Accountability and Corporate Governance: Exploring Multinationals' Reporting Practices. Business Strategy and the Environment, 18, 1-15.

Raar, J. (2002). Environmental Initiatives: Towards Triple Bottom Line Reporting. Corporate Communications, 7, 169-183.

Sahlin-Andersson, K. (2006). Corporate Social Responsibility: A Trend and a Movement, but of what and for what? Emerald Group Publishing Limited 6(5), 595-608.

Uhlaner, L.M., Van Goor-Balk, H.J.M \& Masurel, E. (2004). Family Business and Corporate Social Responsibility in a Sample of Dutch firms. Journal of Small Business and Enterprise Development, 11(2), 186-194.

Wheeler, D. \& Elkington, J. (2001). The End of the Corporate Environmental Report? Or the Advent of Cybernetic Sustainability Reporting and Communication. Business Strategy and the Environment, 10, 1-14. 